\title{
Feeding ecology of two high-order predators from south-eastern Australia: the coastal broadnose and the deepwater sharpnose sevengill sharks
}

\author{
J. Matías Braccini ${ }^{1,2, *}$ \\ ${ }^{1}$ Marine and Freshwater Fisheries Research Institute, Fisheries Victoria, Department of Primary Industries, \\ PO Box 114, Queenscliff, Victoria 3225, Australia \\ ${ }^{2}$ Department of Zoology, University of Melbourne, Parkville, Victoria 3052, Australia
}

\begin{abstract}
Quantifying the feeding ecology of marine predators is essential for understanding their trophic interactions and their potential regulatory effects in marine ecosystems. I quantified the feeding ecology of 2 related predators that overlap only in part in spatial distribution: the coastal broadnose Notorynchus cepedianus and the deepwater sharpnose Heptranchias perlo sevengill sharks. I found the following: These 2 shark species have different diet specialisation patterns, but show similarities in their prey handling mode. $N$. cepedianus has a generalised diet, whereas $H$. perlo shows high specialisation and lower prey diversity. For both shark species, small, medium and large individuals use different strategies for handling different prey groups. H. perlo preys largely on deepwater teleosts, mainly Lepidorhynchus denticulatus, with larger individuals (901 to $1365 \mathrm{~mm}$ total length, TL) also consuming high proportions of large predatory teleosts of the families Gempylidae and Trichiuridae. N. cepedianus has a diverse diet. Small individuals ( $\leq 900 \mathrm{~mm}$ TL) prey largely on teleosts and secondarily on chondrichthyans. Medium individuals (901 to $1520 \mathrm{~mm}$ TL) prey primarily on chondrichthyans and secondarily on teleosts. Chondrichthyans (mainly Mustelus antarcticus) are also the main prey of large N. cepedianus (>1700 mm TL), but this group also shows a greater preference (than small and medium individuals) for fur seals. Despite the overall differences in dietary composition and the minimal overlap in spatial distribution, the 2 shark species consume prey that migrate from deep to coastal waters (ommastrephid squid and gempylid fish).
\end{abstract}

KEY WORDS: Top predator $\cdot$ Feeding ecology $\cdot$ Heptranchias perlo $\cdot$ Notorynchus cepedianus $\cdot$ Shark $\cdot$ Cow sharks · Hexanchidae

\section{INTRODUCTION}

As a group, sharks are tertiary consumers and many species occupy the upper trophic levels (Cortés 1999). Fieldwork and modelling studies indicate that some shark species may be important in structuring marine communities (Cortés 1999, Stevens et al. 2000, Bascompte et al. 2005, Heithaus 2005, Shepherd \& Myers 2005, Myers et al. 2007). However, there is currently little quantitative information on the feeding ecology of sharks (Wetherbee \& Cortés 2004), particularly for deepwater and large top-predatory species. For these species less information is available than for their shal- low-water and smaller counterparts given the logistic constraints of collecting deepwater and large sharks. Hence, quantifying the feeding ecology of these species is essential for modelling their trophic interactions and their potential regulatory effects in the structure and function of marine ecosystems.

Cow sharks (Hexanchidae) are large top-predatory sharks; as a group, cow sharks have a higher trophic level than any other shark group (Cortés 1999). Within the hexanchids, the broadnose sevengill shark Notorynchus cepedianus exhibited the highest trophic level among 149 shark species (Cortés 1999) — even higher than the great white shark Carcharodon carcharias- 
due to the high contribution of elasmobranchs to its diet. The sharpnose sevengill shark Heptranchias perlo is a less studied species that is considered to be a top predator within the marine communities it inhabits (Frentzel-Beyme \& Köster 2002).

Notorynchus cepedianus and Heptranchias perlo have bladelike teeth on the upper jaw and combshaped teeth on the lower jaw, as well as comparable body shapes, although $N$. cepedianus attains a larger body size ( $3 \mathrm{~m}$ TL). These shark species have little overlap in spatial distribution. $N$. cepedianus is commonly found in temperate waters no deeper than $200 \mathrm{~m}$, although larger individuals can range into deeper waters offshore (Bass et al. 1975, Compagno 1984, Last \& Stevens 1994). H. perlo is commonly found in tropical and temperate depths between 27 and 720 m, occasionally down to 1000 m, (Bass et al. 1975, Compagno 1984, Last \& Stevens 1994, Frentzel-Beyme \& Köster 2002). N. cepedianus and H. perlo are widely distributed around the world (Last \& Stevens 1994), but their feeding ecologies are only known for specific areas. Studies in California, USA (Ebert 1986, 1989), southern Africa (Ebert 1991a) and north Patagonia, Argentina (Lucifora et al. 2005), showed that N. cepedianus preys on chondrichthyans, teleosts, marine mammals, molluscs, lampreys and decapod crustaceans, shifting from a teleost-based to a chondrichthyan-based diet with ontogeny (Ebert 2002). At the Great Meteor seamount, eastern Atlantic, H. perlo preys mainly on teleosts and cephalopods, and to a lesser extent on chondrichthyans (Frentzel-Beyme \& Köster 2002), whereas, off the coast of Tunisia, crustaceans are the second-most consumed prey after teleosts (Capapé 1980). For Australia, there is no information on the feeding ecology of any sevengill shark species and, therefore, no knowledge on the ecological role of these predators or on their interactions with other species. In south-eastern Australia, N. cepedianus is the only high-order predatory shark to exhibit an increase in abundance from the 1970s (Walker et al. 2005). As for other deepwater systems, H. perlo is likely to be a top predator of the Australian continental slope. It is therefore essential to quantify the feeding ecology of these species to understand their potential regulatory effects across the south-eastern Australia ecosystems.

Australia is currently embracing an ecosystembased approach to the management of marine resources. For the implementation of such an approach, it is essential to quantify the feeding ecology of marine organisms, as this information is used as a proxy to their trophic interactions in ecosystem models. The feeding ecology information of high-order predators is particularly scarce. Therefore, there is a current need to continue improving our understanding of the feed- ing ecology of this trophic group, particularly of the feeding ecology of Notorynchus cepedianus and Heptranchias perlo in Australian waters. Hence, the specific aims of this study were to: (1) determine the feeding periodicity and prey handling strategies of these shark species, (2) quantify their dietary composition and (3) identify their diet breadth and diet specialisation strategies.

\section{MATERIALS AND METHODS}

Sampling. Specimens were collected from the bycatch of the Australian Southern and Eastern Scalefish and Shark Fishery. Individuals of Notorynchus cepedianus were collected opportunistically between 30 and $146 \mathrm{~m}$ depth from shark gillnet and trawl vessels operating in waters of South Australia and Victoria, Australia, on a monthly basis between 2002 and 2004. Individuals of Heptranchias perlo were collected opportunistically between 200 and $476 \mathrm{~m}$ depth from trawl vessels operating in Victoria, between February and May 2003. Each specimen was sexed and measured (total length [TL] $\pm 1 \mathrm{~mm}$ ).

Laboratory processing. Feeding ecology was determined from prey identification and analysis of stomach contents. The stomach of each shark was removed and stored frozen, and the contents were identified in the laboratory to the lowest taxon practical.

Overall diet. Diet was assessed by species and size class, based on known ontogenetic shifts in the diet of Notorynchus cepedianus in California, southern Africa (Ebert 2002) and north Patagonia (Lucifora et al. 2005), and the sizes at maturation of the 2 species (Ebert 1989, Frentzel-Beyme \& Köster 2002, Lucifora et al. 2005). The following size classes were considered for Heptranchias perlo, small ( $\leq 900 \mathrm{~mm} \mathrm{TL})$ and large (901 to $1400 \mathrm{~mm} \mathrm{TL}$ ), and for $N$. cepedianus, small ( $\leq 900 \mathrm{~mm} \mathrm{TL}$ ), medium (901 to $1700 \mathrm{~mm}$ TL) and large (>1700 mm TL).

Notorynchus cepedianus can be attracted to gillnets to feed on entangled prey (author's pers. obs.); hence, the degree of digestion of each prey item was recorded as fresh or digested to determine the degree of netfeeding (Bethea et al. 2004). Fresh prey had no sign of digestion. Stomachs containing fresh prey items normally caught by gillnets were excluded from further analyses. Likewise, Heptranchias perlo may occasionally feed while caught in the trawl nets (author's pers. obs.), so stomachs containing fresh prey items normally caught by this gear were also excluded from further analyses.

Prey diversity. Cumulative prey diversity curves were used to determine the minimum number of stomachs required for a precise description of dietary com- 
position (Ferry \& Cailliet 1996). Items such as sponges, hydroids and algae were considered incidental, and were excluded from the analysis. The cumulative number of randomly pooled stomachs was plotted against the cumulative diversity of stomach contents. Diversity was calculated using the pooled quadrat method based on the Brillouin index of diversity (HZ; Pielou 1966). To ensure that curves reached an asymptotic value, 100 random orders of stomachs (curves) were calculated and the mean $( \pm \mathrm{SD})$ was plotted. Diversity curves were considered asymptotic if at least 2 previous values to the total sample diversity were in the range of the asymptotic diversity \pm 0.05 value (Koen Alonso et al. 2002). Diversity curves were calculated for each species and size combination.

Feeding periodicity and prey handling. Stomach fullness (SF), and the number and body parts of prey (PBPs) found in each stomach were recorded to determine the feeding pattern for each species and size combination. SF was recorded using a quarterly scale (1: $1-25 \%$ full; 2 : $26-50 \%$ full; $3: 51-75 \%$ full; 4 : $76-100 \%$ full; Braccini et al. 2005). PBPs were classified as whole prey, head only and body only. Loglikelihood ratios (Zar 1999) were used to test for differences in the distribution of SF and PBPs of each species/size group. The PBP analysis was done for each of the following taxonomic groups: cephalopods, chondrichthyans, teleosts and fur seals (large Notorynchus cepedianus only).

Prey importance. For each species and size combination, prey item importance was evaluated using percentage mass $(\% \mathrm{M})$, percentage number $(\% \mathrm{~N})$, percentage frequency of occurrence (\%FO) and percentage index of relative importance (\%IRI; Pinkas et al. 1971, Cortés 1997). These diet descriptors only provide point estimates of prey importance with no measure of uncertainty around its estimation (Tirasin \& Jørgensen 1999). Hence, bootstrap methods (1000 replicates; Haddon 2001) were used to estimate $95 \%$ CIs (2.5th and 97.5th percentiles) around estimates of the dietary parameters. From the original data matrix, random samples of the observations (i.e. each individual stomach) with replacement were generated to obtain the probability distribution of prey importance parameters (Braccini et al. 2005).

Intraspecific diet comparisons. The effect of the factor size was tested using \%IRI data for the main prey items (mean \%IRI > 5\%). Unidentified teleosts, unidentified molluscs and other unidentified materials were excluded from the comparative analysis as they may contain remnants of $>1$ dietary category (White et al. 2004). Non-parametric multidimensional scaling (nMDS) on Bray-Curtis similarity measures (Clarke 1993) were used to visualize patterns of variation in dietary composition. A 1-way non-parametric permutation multivariate analysis of variance (PERMANOVA) using Bray-Curtis distances (Anderson 2001) was used to test for the effect of the factor size class (small or large for Heptranchias perlo; small, medium, or large for Notorynchus cepedianus) on dietary composition. Size was treated as a fixed factor. Equal sample sizes $(n=100)$ were used. Samples were randomly selected from the 1000 bootstrapped values of \%IRI for each species/size group.

Diet breadth. Levin's index $\beta$ (Krebs 1989) was used to determine the diet breadth of the species/size groups studied. The index was calculated as:

$$
\beta=\frac{1}{\sum P_{i}^{2}}
$$

where $P_{i}$ is the proportion (derived from \%IRI) of individuals using the $i$ th resource (prey item). The values ranged from 1 (highly specialised diet) to the total number of prey categories (the broadest diet).

Levin's index was calculated 1000 times using the bootstrapped \%IRI values to estimate $95 \%$ CIs around a mean diet breadth estimate.

Diet specialisation. For the different species/size groups, diet specialisation was identified by plotting the prey-specific abundance $\left(P_{i}\right)$ of the main prey groups (crustaceans, cephalopods, chondrichthyans and teleosts) against a point estimate of \%FO (Amundsen et al. 1996). Prey-specific abundance refers to the relative abundance among prey species found in the stomachs. This was calculated as the number of prey $i$ divided by the total number of prey in the stomachs that contained prey $i$, expressed as a percentage. In Amundsen's method, any prey located close to $100 \% P_{i}$ and $100 \%$ FO represents population specialisation.

\section{RESULTS}

\section{Overall diet}

The stomach contents and fullness of 116 Heptranchias perlo and 181 Notorynchus cepedianus were examined. In all, there were 67 small (485 to $900 \mathrm{~mm}$ TL) and 49 large (901 to $1365 \mathrm{~mm}$ TL) H. perlo; and 39 small (550 to $895 \mathrm{~mm} \mathrm{TL}$ ), 129 medium (901 to $1520 \mathrm{~mm}$ TL) and 13 large (1740 to $2740 \mathrm{~mm}$ TL) $N$. cepedianus.

\section{Prey diversity}

Cumulative prey diversity reached a stable level at 80 and 100 stomachs for the overall diet of Heptranchias perlo and Notorynchus cepedianus (Fig. 1). $N$. cepedianus had a more diverse diet than did $H$. perlo, with prey diversity of medium $N$. cepedianus 


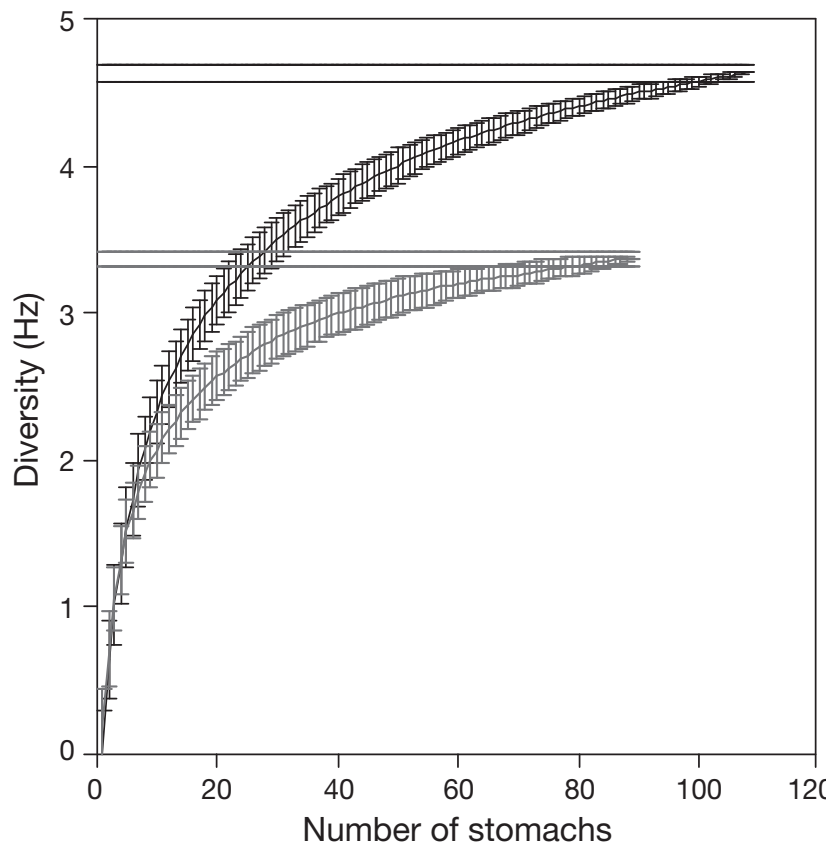

Fig. 1. Heptranchias perlo and Notorynchus cepedianus. Cumulative diversity of prey items for the overall diet of $H$. perlo (grey) and $N$. cepedianus (black). Straight lines: range of asymptotic diversity \pm 0.05 . Data were mean $\pm \mathrm{SD}$

being higher than that for the other groups. For small and large $H$. perlo and medium $N$. cepedianus, cumulative prey diversity curves reached stable levels at 50, 30 and 65 stomachs, respectively (Fig. 2). For small and large $N$. cepedianus, however, the curves did not reach an asymptote (Fig. 2), indicating that more stomachs are needed for a more precise description of their diet.

\section{Feeding periodicity and prey handling}

Of the stomachs of Heptranchias perlo and Notorynchus cepedianus examined, 88 (76\%) and 110 (61\%), respectively, contained prey. Small (80\%) and large $(71 \%) H$. perlo showed higher percentages of stomachs with prey than small (66\%) and medium

Table 1. Heptranchias perlo, Notorynchus cepedianus. Loglikelihood ratios testing for differences in the distribution of stomach fullness values ( $\mathrm{df}=3$ ). $1: 1-25 \%$ full; $2: 26-50$ full; 3: $51-75 \%$ full; $4: 76-100 \%$ full

\begin{tabular}{|lccccccc|}
\hline \multirow{2}{*}{ Group } & \multicolumn{9}{c|}{ Stomach fullness (\%) } & \multirow{2}{*}{ G } & $\mathrm{p}$ \\
& 1 & 2 & 3 & 4 & & \\
\hline Small H. perlo & 29 & 31 & 22 & 18 & 2.4 & 0.49 \\
Large H. perlo & 14 & 43 & 26 & 17 & 6.6 & 0.09 \\
Small N. cepedianus & 44 & 16 & 12 & 28 & 6.1 & 0.11 \\
Medium N. cepedianus & 31 & 26 & 14 & 29 & 5.2 & 0.16 \\
Large N. cepedianus & 31 & 15 & 15 & 38 & 2.1 & 0.55 \\
\hline
\end{tabular}

(55\%) N. cepedianus. Large N. cepedianus always had prey in their stomachs. For stomachs with prey, the distribution of SF was relatively even in each category. There were no significant differences among the frequency of individuals in each SF category for each species/size group (Table 1). A consistent pattern of number of prey per stomach was found across the species/size groups. Stomachs contained mostly 1 or 2 items (Fig. 3), but up to 11 small teleosts were found in 1 stomach of a small $H$. perlo. PBPs found in stomachs of the different shark groups varied with prey type. Cephalopods were mostly found whole (Table 2). Teleosts were mostly found whole in stomachs of small and large $H$. perlo (Table 2). Heads and body portions found in $H$. perlo stomachs corresponded to largesized predatory teleosts of the family Trichiuridae and Gempylidae. Teleosts were mostly found as body portions in the stomachs of small, medium and large $N$. cepedianus (Table 2). Teleosts found whole corresponded to small-sized species $(<0.3 \mathrm{~m}$ TL). Chondrichthyans were mostly found whole or as body portions in stomachs of small $N$. cepedianus (Table 2) and mostly as body portions in stomachs of medium and large individuals (Table 2). Chondrichthyans found whole corresponded to small-sized species, whereas those found as body portions corresponded to mediumsized species $(<1 \mathrm{~m} \mathrm{TL})$. All fur seals were found as body portions.

\section{Prey importance}

The stomachs of small Heptranchias perlo contained 23 taxonomic levels of prey items: 2 crustaceans, 5 cephalopods, 1 chondrichthyan and 15 teleosts (Table A1 available in MEPS Electronic Supplementary Material at: www.int-res.com/articles/suppl/ m371p273_app.pdf). Teleosts were the most important prey group. Lepidorhynchus denticulatus was the dominant prey item, contributing the highest values of $\% \mathrm{M}(26.65 \%), \%$ FO (23.48\%) and \%IRI (37.63\%), and the second highest value of $\% \mathrm{~N}(15.96 \%)$. The secondmost dominant prey by mass $(12.52 \%)$, occurrence $(19.97 \%)$ and \%IRI (30.65\%) was Apogonops anomalus, which showed the highest \%N (28.28\%). Teleosts from the families Trichiuridae and Gempylidae and ommastrephid squids (mainly Nototodarus gouldi) were also important. Decapod crustaceans were not important as they contributed $<1 \%$ of \%IRI.

The stomachs of large Heptranchias perlo contained 17 taxonomic levels of prey items: 1 crustacean, 3 cephalopods and 13 teleosts (Table A1). Teleosts were the most important prey group. Lepidorhynchus denticulatus was the dominant prey item, contributing the highest values of $\% \mathrm{~N}(28.01 \%), \% \mathrm{FO}(40.15 \%)$ and 

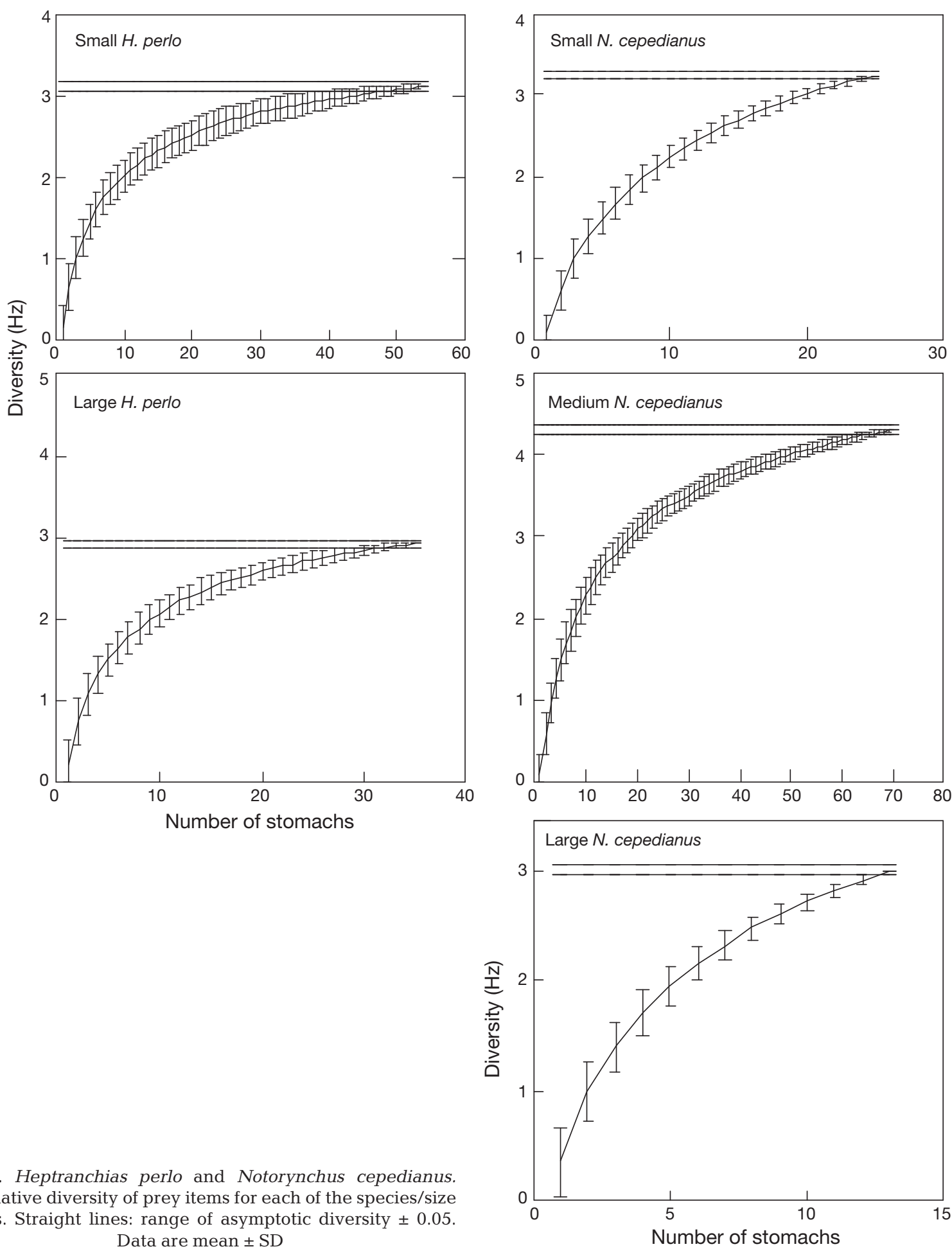

Fig. 2. Heptranchias perlo and Notorynchus cepedianus. Cumulative diversity of prey items for each of the species/size groups. Straight lines: range of asymptotic diversity \pm 0.05 . Data are mean \pm SD

\%IRI $(49.44 \%)$, and the third highest value of \%M $(12.49 \%)$. Teleosts from the families Gempylidae and Trichiuridae were the second- and third-most dominant prey by \%IRI (15.45 and $12.60 \%$, respectively), with Trichiuridae showing the highest \%M (18.09\%). Other teleost species such as Paraulopus nigripinnis

and Apogonops anomalus were also important. Cephalopods and decapod crustaceans were not important as they contributed $<1 \%$ of $\%$ IRI.

The stomachs of small Notorynchus cepedianus contained 20 taxonomic levels of prey items: 1 crustacean, 4 cephalopods, 8 chondrichthyans, 5 teleosts, 1 fur 


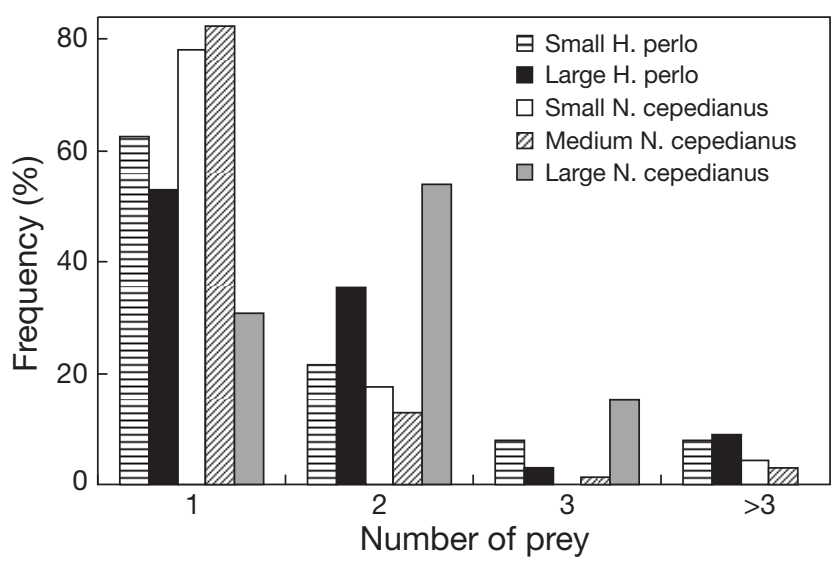

Fig. 3. Heptranchias perlo and Notorynchus cepedianus. Frequency of different numbers of prey found in stomachs of $H$. perlo and $N$. cepedianus

seal and unidentified animal material (Table A2 available in MEPS Electronic Supplementary Material at: www.int-res.com/articles/suppl/m371p273_app.pdf). Unidentified teleosts were the dominant prey item, contributing the highest values of $\% \mathrm{~N}(12.56 \%), \% \mathrm{FO}$ $(15.99 \%)$ and \%IRI $(23.19 \%)$. The second-most dominant prey by number (8.96\%) and \%IRI (13.35\%) was Mustelus antarcticus, which showed the highest \%M (15.33\%). Myliobatis australis and ommastrephid squids were the third- and fourth-most dominant prey by \%IRI (9.75 and $8.15 \%$, respectively). Other important prey included Urolophus paucimaculatus and $U$. cruciatus. Decapod crustaceans and fur seals were less important.

The stomachs of medium Notorynchus cepedianus contained 43 taxonomic levels of prey items: 2 crustacean, 6 cephalopods, 14 chondrichthyans, 19 teleosts and 2 fur seals (Table A2). Myliobatis australis was the dominant prey item by \%M (14.24\%) and \%IRI $(17.17 \%)$. The second-most dominant prey by mass (14.21\%) and \%IRI (13.31\%) was Callorhinchus milii. Other important prey included unidentified teleosts, ommastrephid squids and unidentified chondrichthyans. Decapod crustaceans and fur seals were less important.
The stomachs of large Notorynchus cepedianus contained 19 taxonomic levels of prey items: 1 cephalopod, 10 chondrichthyans, 6 teleosts and 2 fur seals (Table A2). Mustelus antarcticus was by far the dominant prey item by all dietary metrics. The secondmost dominant prey by number $(8.71 \%)$, occurrence $(15.37 \%)$ and \%IRI (8.99\%) were unidentified teleosts. Other important prey included conspecifics and fur seals (Otariidae). Cephalopods were not important.

There was variability around the estimation of overall mean \%IRI when the mean values obtained from bootstrapping were compared with those obtained from point estimates of overall diet (Tables A1 \& A2). For important prey, variability ranged up to 4 and $2 \%$ for small and large Heptranchias perlo, respectively, and to 15,4 and $17 \%$ for small, medium and large Notorynchus cepedianus, respectively. Variability was higher for less important prey and ranged up to 16 and $14 \%$ for small and large $H$. perlo, respectively, and to 19,10 and $30 \%$ for small, medium and large $N$. cepedianus, respectively.

\section{Intraspecific diet comparisons}

There was a significant effect of the factor size in the dietary composition of Heptranchias perlo (Table 3) and Notorynchus cepedianus (Table 3). Small and large $H$. perlo consumed similar prey items, but in different proportions (Table A1), and hence had different diets. This was reflected in their clustering pattern, where small and large $H$. perlo formed 2 separate clus-

Table 3. Heptranchias perlo and Notorynchus cepedianus. PERMANOVA testing for the effects of the factor size class on dietary composition

\begin{tabular}{|lccc|}
\hline Factor & df & $F$ & $p$ \\
\hline H. perlo $(\mathrm{n}=100)$ & 1 & 260.69 & 0.0002 \\
Size & 198 & & \\
Residual & & & \\
$\begin{array}{l}\text { N. cepedianus }(\mathrm{n}=100) \\
\text { Size }\end{array}$ & 2 & 262.72 & 0.0002 \\
Residual & 297 & & \\
\hline
\end{tabular}

Table 2. Heptranchias perlo and Notorynchus cepedianus. Log-likelihood ratios testing for differences in the distribution of prey body parts found in stomachs $(\mathrm{df}=2)$. ND: no data

\begin{tabular}{|c|c|c|c|c|c|c|c|c|c|c|c|c|c|c|c|}
\hline \multirow[t]{2}{*}{ Group } & \multicolumn{3}{|c|}{ Cephalopods (\%) } & \multirow[t]{2}{*}{$G$} & \multirow[t]{2}{*}{$\mathrm{p}$} & \multicolumn{3}{|c|}{ Teleosts (\%) } & \multirow[t]{2}{*}{$G$} & \multirow[t]{2}{*}{$\mathrm{p}$} & \multicolumn{3}{|c|}{ Chondrichthyans (\%) } & \multirow[t]{2}{*}{$G$} & \multirow[t]{2}{*}{$\mathrm{p}$} \\
\hline & Whole & Head & Body & & & Whole & Head & Body & & & Whole & Head & Body & & \\
\hline Small H. perlo & 75 & 12.5 & 12.5 & 18.1 & $<0.05$ & 67 & 10 & 23 & 403.8 & $<0.05$ & ND & ND & ND & ND & ND \\
\hline Large $H$. perlo & 75 & 0 & 25 & 6.1 & $<0.05$ & 65 & 11 & 24 & 218.4 & $<0.05$ & ND & ND & ND & ND & ND \\
\hline Small N. cepedianus & 75 & 0 & 25 & 6.1 & $<0.05$ & 25 & 0 & 75 & 20.9 & $<0.05$ & 43 & 7 & 50 & 39.4 & $<0.05$ \\
\hline Medium N. cepedianus & $S \quad 77$ & 8 & 15 & 40.5 & $<0.05$ & 37 & 10 & 53 & 118.1 & $<0.05$ & 21 & 8 & 71 & 175.9 & $<0.05$ \\
\hline Large $N$. cepedianus & ND & ND & ND & ND & ND & 25 & 12 & 63 & 15.5 & $<0.05$ & 33 & 9 & 58 & 31.1 & $<0.05$ \\
\hline
\end{tabular}



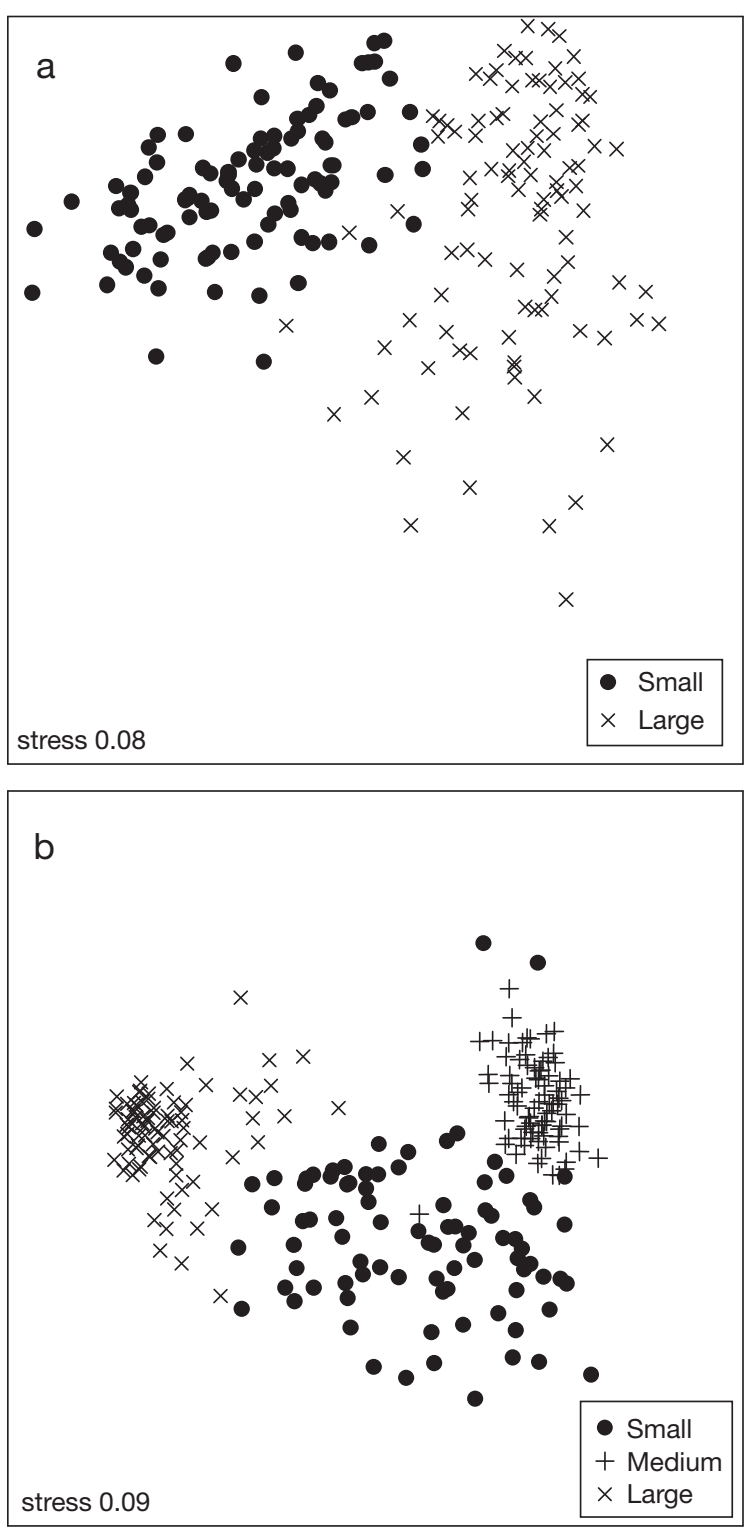

Fig. 4. Heptranchias perlo and Notorynchus cepedianus. Non-parametric multidimensional scaling ordination of the stomach contents of (a) small and large H. perlo and (b) small, medium and large $N$. cepedianus

ters (Fig. 4a). Samples of small, medium and large $N$. cepedianus were also separated into 3 groups (Fig. 4b, pairwise comparisons). Overall, these size classes also preyed on similar items, but, as for $H$. perlo, they consumed them in different proportions (Table A2).

\section{Diet breadth}

Small and large Heptranchias perlo showed a narrow diet breadth and a similar distribution of breadth values (Fig. 5), averaging 3.70 (median: 3.65; 95\% CI:
2.61 to 5.00$)$ for small and $3.27(3.22 ; 2.09$ to 4.76$)$ for large individuals, respectively. These distributions were different in comparison to the diet breadth distributions of small, medium and large $N$. cepedianus, which showed higher dispersion (Fig. 5). Diet breadth averaged 6.12 (5.99; 3.19 to 9.84) for small individuals, $9.24(9.13 ; 5.36$ to 14.15$)$ for medium individuals and $3.00(2.61 ; 1.45$ to 6.52$)$ for large individuals.

\section{Diet specialisation}

Small and large Heptranchias perlo showed a similar specialisation pattern (Fig. 6). For both shark groups, the population was specialised on teleost consumption, and only a few individuals specialised on crustaceans. Notorynchus cepedianus showed a different specialisation pattern (Fig. 6). Small individuals showed a high between-phenotype contribution (i.e. variation in resource use among individuals; Amundsen et al. 1996) to the diet breadth, with some individuals consuming chondrichthyans, some consuming teleosts, some consuming cephalopods and a few consuming crustaceans. Medium individuals had a similar pattern to small individuals, with a higher degree of specialisation on chondrichthyans and teleosts. Large individuals showed population specialisation on chondrichthyans, but this specialisation pattern was not as distinct as for $H$. perlo given the important contribution of teleosts to the diet of large $N$. cepedianus.

\section{DISCUSSION}

\section{Feeding periodicity and prey handling}

A high percentage of Notorynchus cepedianus (39\%) and to a lesser extent of Heptranchias perlo (24\%) had empty stomachs. In addition, for stomachs with prey, both species showed similar distributions of SF values and a low number of prey per stomach. These findings are consistent with other feeding periodicity studies of sharks (e.g. Simpfendorfer et al. 2001, Braccini et al. 2005), supporting the hypothesis that sharks are intermittent feeders. For intermittent feeders, short periods of active feeding are followed by longer periods of reduced predatory activity (Wetherbee et al. 1990, Wetherbee \& Cortés 2004). Predatory activity of intermittent feeders, however, can vary with body size. Given that specific metabolic rate decreases with increasing body size (Schmidt-Nielsen 1984), for a given species, smaller individuals would have higher energetic requirements and consumption rates. Hence, smaller individuals would feed more frequently and show a higher percentage of stomachs with prey (Lucifora et al. 2006). This size- 


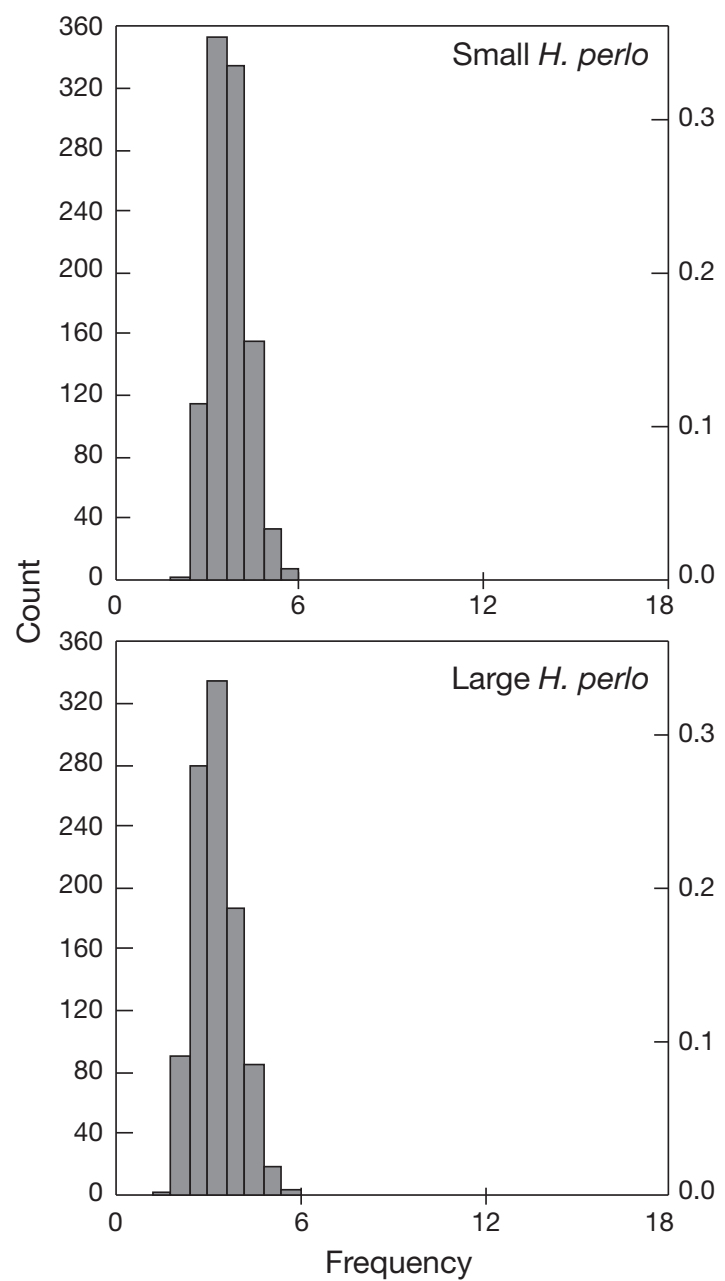

Fig. 5. Heptranchias perlo and Notorynchus cepedianus. Frequency distribution of diet breadth values for small and large $H$. perlo and for small, medium and large $N$. cepedianus ( $\mathrm{n}=1000$ replicates)

related pattern has been reported for $N$. cepedianus in north Patagonia (Lucifora et al. 2005) and other shark species (e.g. Bethea et al. 2006, Lucifora et al. 2006). Our findings support this hypothesis as small individuals of $H$. perlo and $N$. cepedianus showed a higher percentage of stomachs containing prey than larger individuals. The occurrence of a high percentage of stomachs with prey
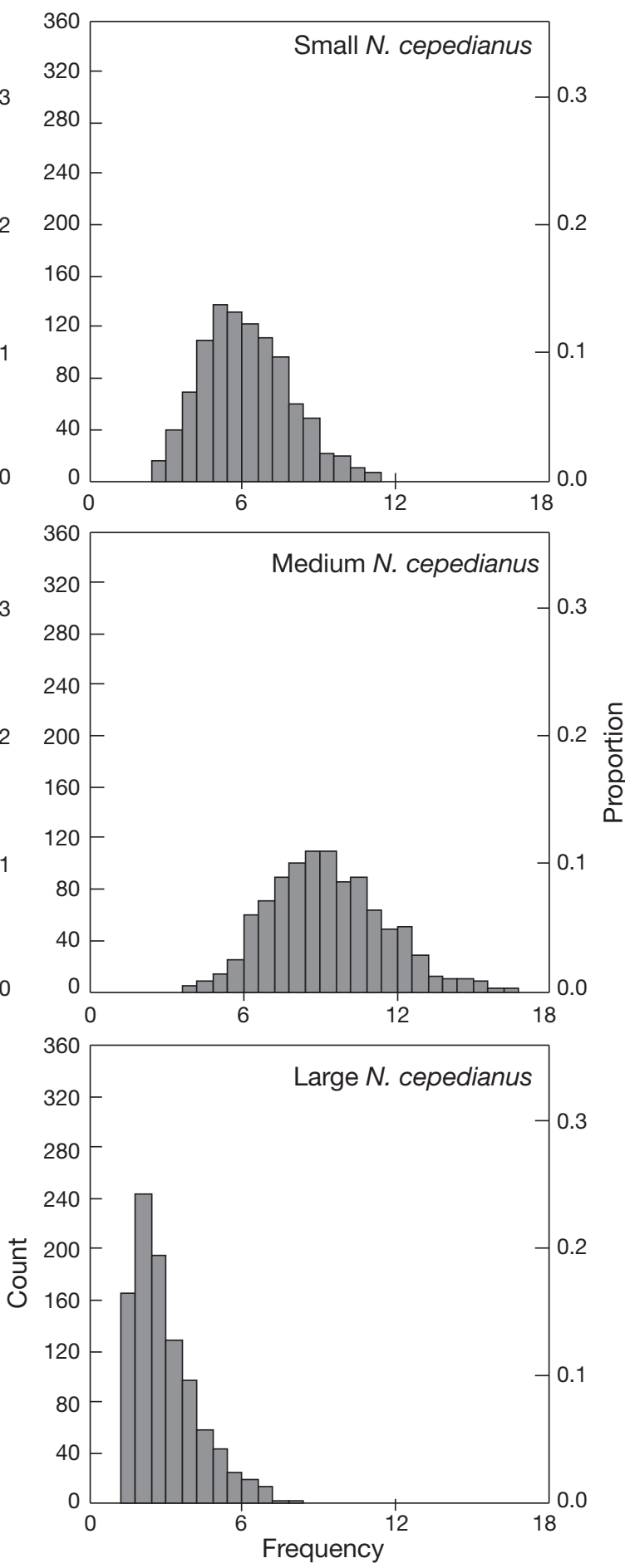

for large $N$. cepedianus is considered an artefact of the low sample size $(n=13)$.

Maximum prey size and prey type is commonly determined by predator gape size, with most piscivorous fish ingesting prey whole (Scharf et al. 1997). However, large predators such as great white Carcharodon carcharias, bull Carcharhinus leucas and tiger 


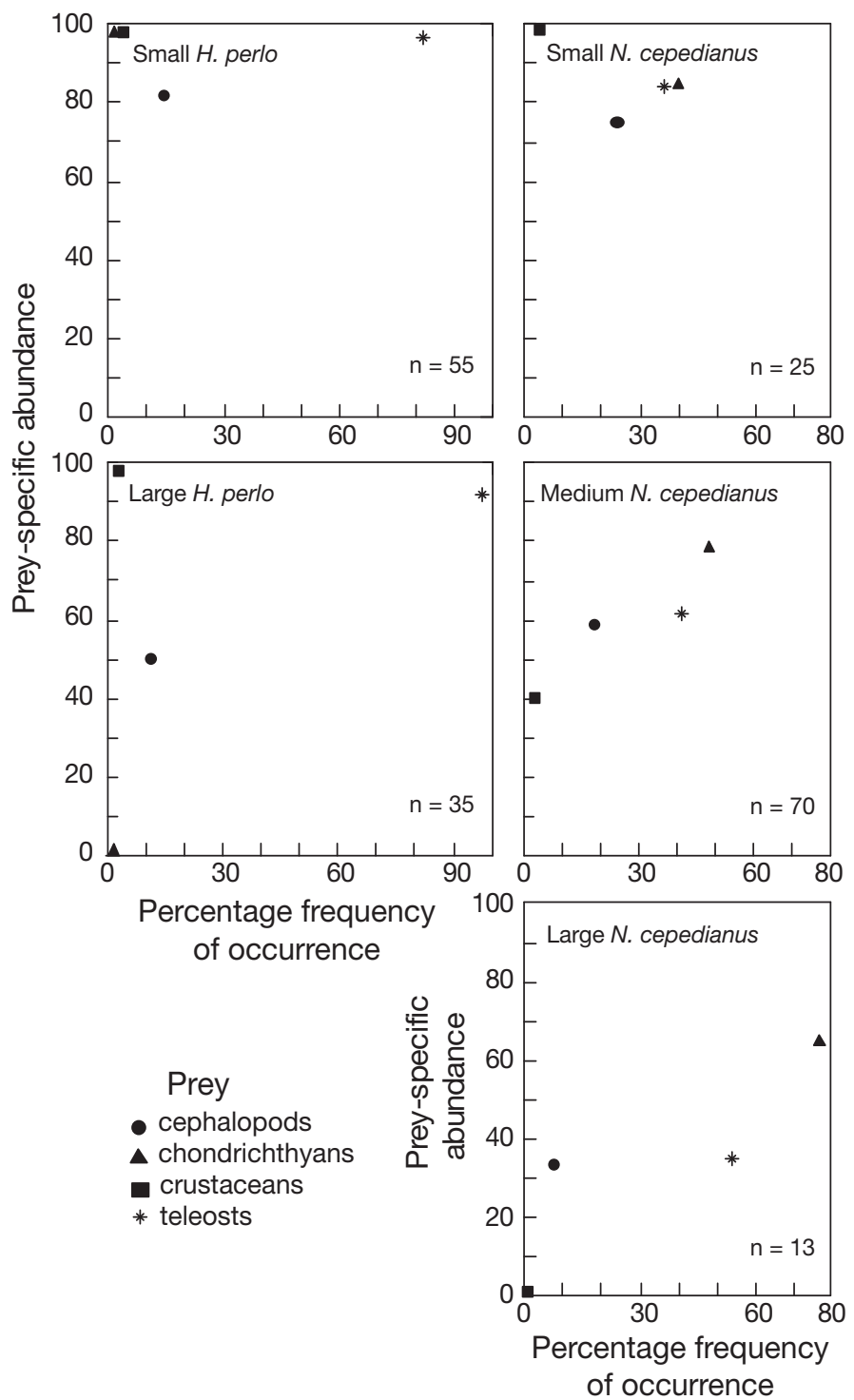

Fig. 6. Heptranchias perlo and Notorynchus cepedianus. Graphical representation of the diet specialisation of small and large $H$. perlo and of small, medium and large $N$. cepedianus. Prey-specific abundance plotted against percentage frequency of occurrence of the main prey categories given in the key

Galeocerdo cuvier sharks exhibit different prey handling strategies that allow them to evade gape limitations (Lucifora et al. 2006). In this way, these species can feed on large prey (marine mammals, sea turtles and chondrichthyans) by cutting pieces off their prey using their large serrated teeth (Frazzetta 1988, Lucifora et al. 2006). Heptranchias perlo and Notorynchus cepedianus have upper jaw teeth with hooked cusps and small lateral cusplets and, in the lower jaw, wide comb-shaped teeth, each with a main mesial cusp and several large distal cusplets (Last \& Stevens 1994). The PBPs found in the stomachs of all sizes of both shark species varied by prey type, suggesting that small, medium and large individuals use different strategies for handling different prey groups. For both shark species, cephalopods were consumed whole and teleosts were consumed whole when small $(<0.3 \mathrm{~m}$ TL) or sectioned when larger. For $N$. cepedianus, fur seals were found as sectioned PBPs, and chondrichthyans found whole corresponded to small-sized species and were mostly found in stomachs of small $N$. cepedianus. For larger individuals, chondrichthyans were mostly found as sectioned PBPs and corresponded to medium-sized species $(<1 \mathrm{~m} \mathrm{TL})$. These findings are consistent with the range of prey handling strategies displayed by $N$. cepedianus, which cut chondrichthyan and marine mammal prey in several pieces after attacking them, except when these prey are small and hence consumed whole (Ebert 1991b, Lucifora et al. 2005). $H$. perlo has the capability to dismember relatively large prey (Frentzel-Beyme \& Köster 2002), suggesting that it also has a range of strategies for handling prey of different sizes. The evolved range of strategies for handling prey of different sizes would allow $N$. cepedianus and $H$. perlo to overcome gape size limitations and exploit a wider range of prey.

\section{Prey importance and diet comparisons}

Heptranchias perlo and Notorynchus cepedianus showed different degrees of variability around estimates of prey importance. For small and large $H$. perlo and medium $N$. cepedianus, variability was low given that the sample size was large enough to precisely describe their dietary composition. For small and large $N$. cepedianus, on the contrary, larger variability was found as sample sizes were not large enough for a precise description of diet. Large variability in dietary composition of sharks would result from the combination of small sample sizes and a high proportion of empty stomachs (Braccini et al. 2005) due to the opportunistic nature of many shark species (Wetherbee et al. 1990). In these cases, the use of bootstrapping methods is particularly appropriate for generating a measure of uncertainty around prey importance parameters. This, in turn, is mostly relevant for representing predatorprey interactions of sharks and other opportunistic marine predator in foodwebs of ecosystem models. Most of these models use \%M data to represent interactions among species; however, when only point estimates of prey importance are used the presence of one very heavy but infrequent prey item can have an unrealistic contribution to diet composition, creating a bias in predator-prey interactions (Braccini et al. 2005). By bootstrapping the diet data matrix, the degree of uncertainty in diet composition can be determined and 
then incorporated when representing the relationships among components of the modelled foodwebs.

Heptranchias perlo mostly consumed demersalbenthic and demersal-pelagic deepwater teleosts. Off Tunisia, deepwater teleosts were also the main prey item (Capapé 1980). At the Great Meteor seamount, however, $H$. perlo showed a more generalised diet, as demersal-benthic deepwater teleosts and cephalopods were almost equally important in its dietary composition (Frentzel-Beyme \& Köster 2002). Notorynchus cepedianus consumed a wide range of demersal prey, including crustaceans, cephalopods, teleosts, chondrichthyans and marine mammals. These findings are consistent with the overall diet spectrum reported in California (Ebert 1986, 1989), southern Africa (Ebert 1991a) and north Patagonia (Lucifora et al. 2005). Although cetaceans were not found in the stomachs of $N$. cepedianus, these prey have been commonly observed by commercial shark fishers during the gutting, particularly in stomachs of larger individuals (Gary Robinson pers. comm.). For N. cepedianus elsewhere and other large top-predatory shark species, predation of cetaceans and other marine mammals also increases with body size (Lowe et al. 1996, Ebert 2002, Lucifora et al. 2005, Estrada et al. 2006).

Heptranchias perlo and Notorynchus cepedianus showed ontogenetic changes in dietary composition. These changes were mostly a result of differences in the proportional contribution of prey to the diet of the different size groups rather than differences in the type of prey consumed by small, medium and large individuals. Small $H$. perlo mostly consumed smallsized teleosts, whereas large $H$. perlo considerably increased the consumption of large predatory teleosts (Gempylidae and Trichiuridae). Teleosts were the main prey of small $N$. cepedianus, whereas individuals between 901 and 1520 mm TL preyed mostly on chondrichthyans. The consumption of fur seals also increased with body size for this species. The diet of $N$. cepedianus in southern Africa, California and Patagonia also changes ontogenetically in a similar fashion (Ebert 2002, Lucifora et al. 2005). The ontogenetic changes that became apparent in the diet of the $2 \mathrm{sev}$ engill shark species indicate an increasing capacity to capture and handle larger prey with increasing body size. Gape size would not be a limitation for small $H$. perlo and $N$. cepedianus for handling prey given that they can consume relatively large prey by sectioning them into manageable pieces. Hence, the observed ontogenetic differences may be attributed to a better hunting capacity of larger sharks to subdue different prey, to differences in habitat use, or both. Differences in habitat use seem a less likely explanation, as individuals from all size classes were collected together. This suggests that small, medium and large individuals would utilize similar habitats; however, information on the movement pattern and habitat use of this species is required to better understand the ontogenetic patterns in diet.

There are 2 caveats to the intraspecific comparative analysis performed. In this study, I described the dietary composition of large Notorynchus cepedianus based on only 13 individuals, assuming this was representative of the whole population off southern Australia. Furthermore, I compared samples collected within a very large region (south-eastern Australia), and seasons and sexes were pooled given the small sample sizes collected for some of the Season $\times$ Sex combinations of $N$. cepedianus and the lack of samples of Heptranchias perlo for winter and spring. Hence, analyses were done without considering sex, season, or a smaller spatial resolution as potential sources of variation based on the assumption that size was the factor explaining most of the variation. Increased sampling of different sexes at different spatial and temporal scales would allow testing of my assumptions and hence would contribute to a better intraspecific comparative characterisation of the dietary composition of these 2 shark species.

\section{Prey diversity, diet breadth and diet specialisation}

Notorynchus cepedianus had a more diverse diet than Heptranchias perlo, so a larger number of stomachs was needed for the characterisation of its overall dietary composition. Also, the diversity curves of small and large $N$. cepedianus did not reach an asymptote, indicating that higher values of prey diversity may result from an increase in stomach sampling. Stomach contents of generalist elasmobranchs show higher prey diversity, and numerous samples are required for a precise description of dietary composition (e.g. Bethea et al. 2004, Braccini et al. 2005). Stomachs of more specialised elasmobranchs commonly show lower prey diversity values, with diversity curves reaching an asymptote at generally <50 stomachs (e.g. Carrassón et al. 1992, Braccini \& Perez 2005). Therefore, the prey diversity values of $N$. cepedianus suggest this species has a more generalist feeding pattern than $H$. perlo.

Heptranchias perlo showed smaller diet breadth values and narrower diet breadth distributions than medium Notorynchus cepedianus, which showed higher and more dispersed values of diet breadth. Small and large $N$. cepedianus showed similar diet breadth values to small and large $H$. perlo due to the under-representation of their dietary composition (i.e. lack of asymptotic prey diversity curves). This diet under-representation is reflected in the higher dispersion of diet breadth values of small and large $N$. cepe- 
dianus. These findings support the hypothesis of a specialised diet for $H$. perlo and a more generalised diet for $N$. cepedianus.

The contrasting diet specialisation patterns of Heptranchias perlo and Notorynchus cepedianus could be related to the diversity of prey these shark species encounter in their primary habitats. Due to the nearuniversal decrease in species diversity with increasing depth (e.g. Rex et al. 1997, Rex \& Etter 1998, Smith \& Brown 2002), a versatile predator like $N$. cepedianus would encounter a wider range of prey on the continental shelf than would $H$. perlo. Higher prey diversity would result in a broader range of prey options and, therefore, a more generalised diet should enable $N$. cepedianus to capitalise on this situation. Alternatively (or, most likely, in combination), slight morphological differences in body form and feeding structure, and differences in foraging behaviour, would also contribute to explaining the specialisation patterns of $H$. perlo and N. cepedianus.

Morphological specialisation of trophic mechanisms is commonly reported for aquatic animals as a strategy for resource partitioning (e.g. Ross 1986, Dejen et al. 2006). Despite sharing similar tooth structure and body morphology, the more slender body and narrower head with pointed snout of Heptranchias perlo would restrict its diet to mainly fish and cephalopod prey, constraining its access to certain food types (e.g. large chondrichthyans, marine mammals). On the contrary, Notorynchus cepedianus attains a larger body size and has a broader and more robust head, allowing it access to a wider range of food types. Observations on the predatory behaviour of $N$. cepedianus revealed several foraging strategies, such as social facilitation, stealth, burst of speed and ambush (Ebert 1991b), which might allow this species access to a range of different prey types. There are presently no reported observations on the foraging strategies of $H$. perlo. There is clearly no obvious and straightforward explanation for the foraging patterns of predators, particularly for large predators such as sharks. Ecological (e.g. prey diversity, abundance and availability), biological (e.g. body form, life history) and behavioural (e.g. foraging strategies) attributes are most likely interacting to establish the resulting foraging patterns. Which of these attributes, if any, contributes the most remains unclear and warrants further examination under a more rigorous hypothesis testing framework.

\section{Conclusions}

Many shark species are long-range foragers, and many marine prey undergo vertical and open oceancoastal migrations. Hence, marine predators with little overlap in spatial distribution could exploit the same migratory prey species. Overall, Notorynchus cepedianus and Heptranchias perlo showed different dietary compositions, diet breadth and specialisation patterns. However, they also consumed prey that migrate from deep to coastal waters (ommastrephid squid and gempylid fish), probably due to morphological and behavioural similarities.

Acknowledgements. I thank M. Gomon, G. Poore and M. Norman for help in the identification of prey items, P. Risley, G. Richardson and the crew of the fishing vessel 'Nungurner' for help in sample collection, and 3 anonymous reviewers for constructive comments on the manuscript. This research was supported by a FRDC grant (FRDC 2002/033) to Terry Walker. Funding for the field and laboratory components was provided by Sea World Research and Rescue Foundation, Royal Zoological Society of New South Wales, Nature Foundation SA and Royal Zoological Society of South Australia.

\section{LITERATURE CITED}

Amundsen PA, Gabler HM, Staldvik FJ (1996) A new approach to graphical analysis of feeding strategy from stomach contents data-modification of the Costello (1990) method. J Fish Biol 48:607-614

Anderson MJ (2001) Permutation tests for univariate or multivariate analysis of variance and regression. Can J Fish Aquat Sci 58:626-639

Bascompte J, Melián CJ, Sala E (2005) Interaction strength combinations and the overfishing of a marine food web. Proc Natl Acad Sci USA 102:5443-5447

Bass AJ, D'Aubrey JD, Kistnasamy N (1975) Sharks of the east coast of southern Africa. V. The families Hexanchidae, Chlamydoselachidae, Heterodontidae, Pristiophoridae and Squatinidae. Investigational Report 43, Oceanographic Research Institute, Durban

Bethea DM, Buckel JA, Carlson JK (2004) Foraging ecology of the early life stages of four sympatric shark species. Mar Ecol Prog Ser 268:245-264

Bethea DM, Carlson JK, Buckel JA, Satterwhite M (2006) Ontogenetic and site related trends in the diet of Atlantic sharpnose shark Rhizoprionodon terraenovae from the northeast Gulf of Mexico. Bull Mar Sci 78:287-307

Braccini JM, Perez JE (2005) Feeding habits of the sandskate Psammobatis extenta (Garman, 1913): sources of variation in dietary composition. Mar Freshw Res 56: 395-403

Braccini JM, Gillanders BM, Walker TI (2005) Sources of variation in the feeding ecology of the piked spurdog (Squalus megalops): implications for inferring predator-prey interactions from overall dietary composition. ICES J Mar Sci 62:1076-1094

Capapé C (1980) Nouvelle description de Heptranchias perlo (Bonnaterre, 1788) (Pisces, Pleurotremata; Hexanchidae). Données sur la biologie de la reproduction et le régime alimentaire des spécimens des côtes tunisiennes. Bull Off Natnl Pech 4:231-264

> Carrassón M, Stefanescu C, Cartes JE (1992) Diets and bathymetric distributions of two bathyal sharks of the Catalan deep sea (western Mediterranean). Mar Ecol Prog Ser 82:21-30

Clarke KR (1993) Non-parametric multivariate analyses of changes in community structure. J Ecol 18:117-143 
Compagno LJV (1984) FAO species catalogue. Sharks of the world. An annotated and illustrated catalogue of shark species known to date. (1) Hexanchiformes to Lamniformes, Vol 4. FAO Fish Synop 125:17-23

Cortés E (1997) A critical review of methods of studying fish feeding based on analysis of stomach contents: application to elasmobranch fishes. Can J Fish Aquat Sci 54:726-738

Cortés E (1999) Standardized diet compositions and trophic levels of sharks. ICES J Mar Sci 56:707-717

Dejen E, Vijverberg J, de Graaf M, Sibbing FA (2006) Predicting and testing resource partitioning in a tropical fish assemblage of zooplanktivorous 'barbs': an ecomorphological approach. J Fish Biol 69:1356-1378

Ebert DA (1986) Aspects on the biology of hexanchid sharks along the California coast. In: Uyeno T, Arai R, Taniuchi T, Matsuura K (eds) Indo-Pacific fish biology. Proceedings of the 2nd international conference on Indo-Pacific fishes. Ichthyological Society of Japan, Tokyo, p 437-449

Ebert DA (1989) Life history of the sevengill shark, Notorynchus cepedianus Peron, in two northern California Bays. Calif Fish Game 75:101-112

Ebert DA (1991a) Diet of the sevengill shark Notorynchus cepedianus in the temperate coastal waters of southern Africa. S Afr J Mar Sci 11:565-572

Ebert DA (1991b) Observations on the predatory behaviour of the sevengill shark Notorynchus cepedianus. S Afr J Mar Sci 11:455-465

Ebert DA (2002) Ontogenetic changes in the diet of the sevengill shark (Notorynchus cepedianus). Mar Freshw Res 53:517-523

Estrada JA, Rice AN, Natanson LJ, Skomal GB (2006) Use of isotopic analysis of vertebrae in reconstructing ontogenetic feeding ecology in white sharks. Ecology 87:829-834

Ferry LA, Cailliet GM (1996) Sample size and data analysis: Are we characterizing and comparing diet properly? In: MacKinlay D, Shearer K (eds) Feeding ecology and nutrition in fish. Proceedings of the symposium on the feeding ecology and nutrition in fish, international congress on the biology of fishes. American Fisheries Society, San Francisco, CA, p 71-80

Frazzetta TH (1988) The mechanics of cutting and the form of shark teeth (Chondrichthyes, Elasmobranchii). Zoomorphology 108:93-107

Frentzel-Beyme BZ, Köster FW (2002) On the biology of the sharpnose sevengill shark, Heptranchias perlo, from the Great Meteor Seamount (central eastern Atlantic). In: Vacchi M, La Mesa G, Serena F, Seret B (eds) Proc 4th European Elasmobranch Assoc Meet. Société française d'Ichtyologie SFI, Livorno, p 77-96

Haddon M (2001) Modelling and quantitative methods in fisheries. CRC, Boca Raton, FL

> Heithaus MR (2005) Habitat use and group size of pied cormorants (Phalacrocorax varius) in a seagrass ecosystem: possible effects of food abundance and predation risk. Mar Biol (Berl) 147:27-35

Koen Alonso M, Crespo EA, Garcia NA, Pedraza SN, Mariotti PA, Mora NJ (2002) Fishery and ontogenetic driven changes in the diet of the spiny dogfish, Squalus acanthias, in Patagonian waters, Argentina. Environ Biol Fishes 63:193-202

Krebs CJ (1989) Ecological methodology. Harper Collins, New York

Last PR, Stevens JD (1994) Sharks and rays of Australia. CSIRO Publishing, Melbourne

> Lowe CG, Wetherbee BM, Crow GL, Tester AL (1996) Ontogenetic dietary shifts and feeding behavior of the tiger shark, Galeocerdo cuvier, in Hawaiian waters. Environ
Biol Fishes 47:203-211

Lucifora LO, Menni RC, Escalante AH (2005) Reproduction, abundance and feeding habits of the broadnose sevengill shark Notorynchus cepedianus in north Patagonia, Argentina. Mar Ecol Prog Ser 289:237-244

Lucifora LO, Garcia VB, Menni RC, Escalante AH (2006) Food habits, selectivity, and foraging modes of the school shark Galeorhinus galeus. Mar Ecol Prog Ser 315:259-270

> Myers RA, Baum JK, Shepherd TD, Powers SP, Peterson CH (2007) Cascading effects of the loss of apex predatory sharks from a coastal ocean. Science 315:1846-1850

$>$ Pielou EC (1966) The measurement of diversity in different types of biological collections. J Theor Biol 13:131-144

Pinkas LM, Oliphant S, Iverson ILK (1971) Food habits of albacore, bluefin tuna and bonito in Californian waters. Calif Fish Game 152:1-105

Rex MA, Etter RJ (1998) Bathymetric patterns of body size: implications for deep-sea biodiversity. Deep-Sea Res 45: 103-127

Rex MA, Etter RJ, Stuart CT (1997) Large-scale patterns of species diversity in the deep-sea benthos. In: Ormond R, Gage JD (eds) Marine biodiversity: causes and consequences. Cambridge University Press, Cambridge, p 94-121

Ross ST (1986) Resource partitioning in fish assemblages: a review of field studies. Copeia 1986:352-388

Scharf FS, Buckel JA, Juanes F, Conover DO (1997) Estimating piscine prey size form partial remains: testing for shifts in foraging mode by juvenile bluefish. Environ Biol Fish 49:377-388

Schmidt-Nielsen K (1984) Scaling: Why is animal size so important? Cambridge University Press, Cambridge

Shepherd TD, Myers RA (2005) Direct and indirect fishery effects on small coastal elasmobranchs in the northern Gulf of Mexico. Ecol Lett 8:1095-1104

Simpfendorfer CA, Goodreid A, McAuley RB (2001) Diet of three commercially important shark species from Western Australian waters. Mar Freshw Res 52:975-985

Smith KF, Brown JH (2002) Patterns of diversity, depth range and body size among pelagic fishes along a gradient of depth. Glob Ecol Biogeogr 11:313-322

> Stevens JD, Bonfil R, Dulvy NK, Walker PA (2000) The effects of fishing on sharks, rays, and chimaeras (chondrichthyans), and the implications for marine ecosystems. ICES J Mar Sci 57:476-494

> Tirasin EM, Jørgensen T (1999) An evaluation of the precision of diet description. Mar Ecol Prog Ser 182:243-252

Walker TI, Hudson RJ, Gason AS (2005) Catch evaluation of target, by-product and by-catch species taken by gillnets and longlines in the shark fishery of south-eastern Australia. J Northwest Atl Fish Sci 35:505-530

Wetherbee BM, Cortés E (2004) Food consumption and feeding habits. In: Carrier JF, Musick JA, Heithaus MR (eds) Biology of sharks and their relatives. CRC Press, Boca Raton, FL, p 225-246

Wetherbee BM, Gruber SH, Cortés E (1990) Diet, feeding habits, digestion, and consumption in sharks, with special reference to the lemon shark, Negaprion brevirostris. In: Pratt HL Jr, Gruber SH, Taniuchi T (eds) Elasmobranchs as living resources: advances in biology, ecology, systematics, and the status of the fisheries. NOAA Technical Report NMFS 90, NOAA, Seattle, WA, p 29-47

White WT, Platell ME, Potter IC (2004) Comparisons between the diets of four abundant species of elasmobranchs in a subtropical embayment: implications for resource partitioning. Mar Biol (Berl) 144:439-448

Zar JH (1999) Biostatistical analysis. Prentice Hall, London 